\title{
Comparative Study Between TV Ultrasound Alone And TV Ultrasound With Gel Instillation Sonohystrography In Assessment Of Caesarean Section Scar In Non-Pregnant Women M.R.Fayed, I.I.swedan, A.S.Soliman and W.A.Fawzy Obstetrics and Gynecolog, Dept., Faculty of Medicine, Benha Univ., Benha, Egypt Email:weam.f@yahoo.com
}

\begin{abstract}
Introduction: Isthmocele is a uterine wall defect at the CS scar region. It was linked with the detrimental result of breastfeeding, increased incidence of gynaecological risks. Objective: to equate gel Inflammatory sonohysterography with TV ultrasound only in non-pregnant women in evaluation of caesarean section scar. Methods: This sample consisted of 100 nonpregnant women and the findings of a comparison between TVUS and GIS in the assessment of CS scar; after follow-up from the patients, risk factors and clinical results have been published. The Goldstein Sonohysterography Catheter was administered on all participants subject to complete biography, clinical assessment, TVS alone, and eventual GIS. Result: Caesarean niche occurrence is 25 percent. With reference to the C.S. niche Sonographical assessment by TVS and GIS, there was a statistically important discrepancy in defect length $(\mathrm{P}=0.017)$, defect height $(\mathrm{P}=0.035)$, and myometric thickness adjacent to the defect $(\mathrm{P}=$ 0.013). GIS showed that the triangle parameter by gel instillation sonohysterography was the most studied niche classification (48 percent) Furthermore, semi-circle, droplet and inclusion cyst are 24\%, 16\%, 8\% and 4\%, respectively. niches Conclusion: TVUS and GIS are both successful, but GIS is far more reliable when it comes to determining niche properties.
\end{abstract}

Keywords: TV Ultrasound, Gel Instillation Sonohystrography, Caesarean Section Scar defect.

\section{Introduction}

The C-section (CS) prevalence has risen worldwide in the last several decades. About 1.2 million CS deliveries were made in the USA in 2014. Complications linked to CS have also risen along with the increasing CS rate. The uterine wall defect on the location of the CS scar known as the isthmocele or niche is one of the known complications. Adverse birth results, greater incidence of problems during gynaecology, as well as health signs including postmenstrual bleeding have been linked with this [3].

The frequency of isthmocele in previous research ranged from 6.9 to $69 \%$. Different meanings of isthmocele, numerous study designs and diagnostic methods may trigger the large variability [4]. Different imaging techniques were employed to evaluate an isthmocele that is sometimes visualised in the uterine isthmus. Ultrasound (US) has also substituted other approaches, such as hysterography focused on radiology. Transvaginal ultrasound (TVUS) was an effective form of isthmocele detection. However, contrast-enhanced sonohysterography (CESI) seems to make it easier for non pregnant women to identify and calculate [7].

Gel Instillation Sonography (GIS) is a simple method of diagnostics and less fluid leakage is caused by higher viscosity of the gel. Even if backflow cannot be entirely stopped, GIS provides steady distension for a minimum of 4-5 minutes, which is enough to complete the ultrasound assessment. Small variations in distension in time can be induced by uterine muscle contractions. For better output of GIS, commercial goods containing a gel with a smaller quantity of solved molecules are usable, do not have to manually move gel from one syringe to another [3].

In this research, we intended to relate gel Sonohysterography of instillation and TV ultrasound in non-pregnant women to caesarean section scar alone. In addition, to assess the occurrence of ceaserian scar defects (niche or isthmocele).

\section{Methods and patients}

A prospective retrospective research was performed in Benha University Hospitals on 100 subjects who attended the Department of Obstetrics and Gynecology between June, 2019 and October, 2020.

The ethics committee of the Benha University Hospitals, Benha University, accepted the research procedure. After explanation of the research steps in depth, all patients involved in this study received informed written consent. This research published the comparative findings of TVUS and GIS in the assessment of CS scar; after participants followed up, risk factors and clinical outcomes were reported.

\subsection{Inclusion criteria}

- Women with previous one ceacerian section since at least six monthes.

\subsection{Exclusion criteria}

- known anomaly of uterus,

- Age less than 18 years old

- risk of pelvic inflammatory disease

- presence of cervical cancer.

- pregnancy.

- In the luteal phase without use of contraception.

Both participants subjected to a complete biography, a clinical review, TVS and corresponding GIS alone were conducted using the $26 \mathrm{~cm}$ long and $2.4 \mathrm{~mm}$ diameter Goldstein Sonohysterography Catheter (Cook Medical, Spencer, USA). 
A. Transvaginal A niche known as an anechoic region at the Cesarean Scar site with a depth of at least 1 $\mathrm{mm}$ had been explored in the womb. The width of the niche (vertical gap between the base and apex of the defeat) and the Residual Myometrium Thickness (RMT) are determined when a niche could be found (from the serosal surface of the uterus to the apex of the niche). The United States measurements are detailed in Fig. (1).

\section{B-Gel instillation Sonohysterography}

- Immediately after the TVUS, sonohysterography had been performed. A small catheter (Insemination cannula standard, Laboratoire CCD, Paris, France) had been inserted into the uterus and sterile gel Endosgel, (farco-pharma) which is a sterile gel preparation which has long been used by urologists for intrauretheral instillation before cystocsopy and contains( chlorhexidine gluconate, sodium lactate, methyl hydroxybenzoate ,propyl hydroxybenzoate ,hydroxyethylcellulose and purified water). A syringe had been connected to the base of the catheter and realtime ultrasonographic imaging will be performed with the simultaneous instillation of gel.

- Gel had been infused through the catheter until the patient felt slight menstrual cramps, backflow started or a maximum of $10 \mathrm{~mL}$ had been reached.

- If a niche with a depth of at least $1 \mathrm{~mm}$ can be detected, the same measurements as mentioned above had been repeated in the distended uterus.

\subsection{Statistical analysis}

Patients' data were presented as frequency and percentage for categorical variables, mean and SD for numerical variables. Groups were compared by independent samples Student $\mathrm{t}$-test and $\chi 2$-test for numerical and categorical data, respectively. All data and statistical analyses were handled by statistical package for the social sciences (SPSS, IBM, SPSS Inc.Chicago, USA) computer package version 18 .

\section{Results}

Our study included 100 nonpregnant woman and their mean of age was 35.2 year. The sonographic characteristics of uteri, showed that the mean of endometrial thickness is $5.1 \mathrm{~mm}$ while uterine length and width are 7.3 and $3.8 \mathrm{~cm}$ respectively. The patients who diagnosed as cesarean scar niche are 25\% Table (1).

As regard to symptoms related to C.S niche, $54 \%$ of patients have postmenstrual spotting, $26 \%$ intermenstrual bleeding, $12 \%$ lower abdominal pain and $7 \%$ have other symptoms Table (2).

Regarding Sonographic characteristics evaluation of C.S niche by TVS and GIS, there was a statistically significant difference regarding Length of $\operatorname{defect}(\mathrm{P}=$ $0.017)$, Height of defect $(P=0.035)$, Myometrial thickness adjacent to the defect $(\mathrm{P}=0.013)$ (Table 3$)$.

GIS revealed that triangle parameter was the most observed Niche classification (48\%) by gel instillation sonohysterography. Also, semicircle, droplet and inclusion cyst, other niche classification are $24 \%, 16 \%, 8 \%$ and $4 \%$ respectively Table (4).

Myometrium thickness in patients with niche by TVS and GIS is 3.0 and $3.6 \mathrm{~mm}$ with significant difference between niche and no niche patients ( $\mathrm{p}=0.001)$ Table (5).

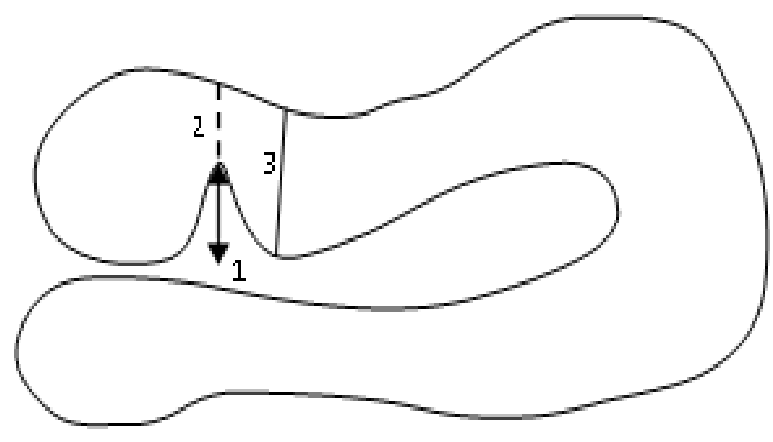

Fig. (1) Schematic diagram demonstrating measurement of depth of the niche (1), thickness of the residual myometrium(2) and total myometrial thickness (3).

Table (1) Sonographic characteristics of uteri of women in the studied patients

\begin{tabular}{|c|c|}
\hline Parameter & Cases $(n=100)$ \\
\hline Endometrial thickness $(\mathbf{m m})_{\text {Mean }+ \text { SD }}$ & $5.1 \pm 2.9$ \\
\hline Uterine length $(\mathrm{cm})_{M e a n+S D}$ & $7.3 \pm 1.2$ \\
\hline Uterine width $(\mathbf{c m})_{\text {Mean }+ \text { SD }}$ & $3.8 \pm 0.7$ \\
\hline Cesarean scar niche $_{\mathrm{No}(\%)}$ & $25(25 \%)$ \\
\hline
\end{tabular}


Table (2) Symptoms related to C.S niche in studied patients.

\begin{tabular}{lc}
\hline Parameter & Cases $(\mathbf{n}=\mathbf{1 0 0})$ \\
\hline Postmenstrual spotting & No $(\%)$ \\
Intermenstrual bleeding & $54(54 \%)$ \\
Lower abdominal pain & $26(26 \%)$ \\
Others & $12(12 \%)$ \\
\hline
\end{tabular}

Table (3) Sonographic characteristics of C.S niche by TVS and GIS.

\begin{tabular}{|c|c|c|c|}
\hline Parameter & TVS & GIS & P value \\
\hline Length of defect $(\mathrm{mm})_{\text {Mean }+\mathrm{SD}}$ & $5.4 \pm 1.3$ & $7.3 \pm 2.4$ & 0.017* \\
\hline Height of defect $(\mathrm{mm})_{\text {Mean }+\mathrm{SD}}$ & $4.6 \pm 1.6$ & $5.2 \pm 2.7$ & $\mathbf{0 . 0 3 5} *$ \\
\hline Myometrial thickness adjacent to the $\operatorname{defect}(\mathrm{mm})_{\text {Mean }+\mathrm{SD}}$ & $7.4 \pm 2.5$ & $9.2 \pm 1.4$ & $0.013 *$ \\
\hline Residual myometrium thickness $(\mathbf{m m})_{M e a n+S D}$ & $3.0 \pm 1.2$ & $3.6 \pm 1.4$ & 0.328 \\
\hline Ratio $(\%)^{1}$ Median (Range) & $35.8(0-91.5)$ & $41.8(0-92.7)$ & 0.126 \\
\hline
\end{tabular}

${ }^{1}$ Ratio between residual myometrium thickness and thickness of the myometrium adjacent to the defect.

*P value is significant

Table (4) Niche classification by gel instillation sonohysterography.

\begin{tabular}{lc}
\hline Parameter & Niche Cases $(\mathbf{n}=\mathbf{2 5}) \mathbf{N o}(\boldsymbol{\%})$ \\
\hline Semicircle & $6(24 \%)$ \\
Triangle & $12(48 \%)$ \\
Droplet & $4(16 \%)$ \\
Inclusion cyst(s) & $2(8 \%)$ \\
Others & $1(4 \%)$ \\
\hline
\end{tabular}

Table (5) Myometrium thickness at site of scar in all patients.

\begin{tabular}{llll}
\hline Myometrium thickness $(\mathbf{m m})$ & Niche $(\mathbf{n}=\mathbf{1 5})$ & $\begin{array}{l}\text { NO niche } \\
(\mathbf{n}=\mathbf{8 5})\end{array}$ & P value \\
\hline TVS Mean +SD & $3.0 \pm 1.2$ & $8.6 \pm 2.8$ & $\mathbf{0 . 0 0 1 *}$ \\
GIS Mean +SD & $3.6 \pm 1.4$ & $9.5 \pm 4.4$ & $\mathbf{0 . 0 0 1 *}$ \\
\hline
\end{tabular}

*P value is significant

\section{Discussion}

In female non-pregnants, the bone scar is evident with transvaginal ultrasonography (TVU). There were many cases of associations between excessive bleeding and a niche, utilising either saline (saline infusion sono hysterography, SIS) or gel (gel instillation sonohysterography, GIS). Post-menstrual spotting in women with a niche seems to be a primary symptom [8].

As for the sonographic traits of women in the patients examined. Mean thickness of endometrial $(\mathrm{mm})$ $(5.1 \pm 2.9 \mathrm{SD})$, mean thickness of uterine $(\mathrm{cm})(7.3 \pm 1.2$ $\mathrm{SD})$. Mean width of uterine $(\mathrm{cm})(3.8 \pm 0.7 \mathrm{SD})$. Caesarean scar niche in $25(25 \%)$ women was found. In studied patients, postmenstrual spotting (54 per cent), intermenstrual bleeding (26 per cent), low abdominal discomfort (12 per cent), and finally other signs were also present in relation to symptoms linked to the C.S niche (7 percent).

Three hundred and seventy-one women is included in the review of [9]. The isthmocele prevalence was $22.4 \%$ based on TVUS and $45.6 \%$ based on SHG. The sensitivity and precision of TVUS in comparison to SHG was 49.1 and 100 percent. Half of the deficiencies identified with SHG (50.9 percent) is therefore also diagnosed with TVUS.

Two hundred and sixty-three women is included in the review of [3]. The prevalence of Niche was $49.6 \%$ for TVU and $64.5 \%$ for GIS. Women with a GIS niche registered post-menstrual spotting more than women without a niche (OR 5.48, CI 1.14-26.48, 95 percent). The post menstrual flickering was greater for women with a residual myometric thickness of 50 per cent of the adjacent myometric thickness than for women with a residual 
myometric thickness of $>50$ per cent of the adjacent myometry (OR 6.13, 95 per cent CI 1.74-21,63). The existence of a niche was not associated with urinary incontinence.

In the analysis of the [2] in all women participating in the report, both observers found caesarean hysterotomy scars. On traditional TVS, 26 (46.4 percent) women found a scar defect in both observers. In two additional instances, Observer 2 identified a scar defect (classified as small). There was 96.4 percent consensus to detect any traditional TVS scar flaw (kappa, 0.93). The observers agreed 100\% in explaining the existence of the flaw. In 24 cases, the defect was triangular and in two cases it was defined as a complete defect without myometric excess of the defect. With SCSH, both observers observed a scar defect in 38 (69.1 percent) women. In one additional instance, Observer 1 identified a scar defect (classified as small). A 98.2 percent consensus was reached (kappa, 0.96) to detect any SCSH scar flaw. SCSH verified all scar defects found on traditional TVS (including just the two additional Observer 1 cases). There was $100 \%$ consensus on the presence of the scar defect on SCSH among the observers. In 36 cases, the defect was triangular and in two cases was declared to be a complete defect, with little myometry left around the defect. SCSH verified the appearance of the 26 scar defects seen on traditional TVS.

We owe niche percentage variations to others because ultrasound is operator based, whereas the outcomes of the same analysis are different between operators.

With respect to the Sonographic properties of the measurement of the C.S niche by TVS and GIS, there were statistically important differences in defect length $(\mathrm{P}=0.017)$, defect height $(\mathrm{P}=0.035)$, defect myometric thickness $(\mathrm{P}=0.013)$. The most observed niche grouping by gel instillation sonohysterography was the triangular parameter. GIS is also more precise in the identification and evaluation of the characteristics of the caesarean niche. These findings are also [11], [6], [2] and [9].

\section{Conclusion}

We may infer that both TVUS and GIS are reliable, but GIS is substantially more accurate in niche characteristics evaluation in post-C.S scar clinical.

\section{References}

[1] R.Antila Långsjö, JU.Mäenpää, H.Huhtala, E.Tomás, S.Staff, Comparison of transvaginal ultrasound and saline contrast sonohysterography in evaluation of cesarean scar defect: a prospective cohort study. Acta obstetricia et gynecologica Scandinavica.vol.9 pp. 30-116,2018.

[2] A.Baranov, G.Gunnarsson, KÅ.Salvesen, PE.Isberg, O.Vikhareva. Assessment of Cesarean hysterotomy scar in non-pregnant women: reliability of transvaginal sonography with and without contrast enhancement. Ultrasound in Obstetrics \& Gynecology.vol.47,499-505,2016.

[3] AJM.Bij de Vaate, HAM.Br€olmann, LF.van der Voet, JW.van der Slikke, S .Veersema, JAF.Huirne Ultrasound evaluation of the caesarean scar: relation between a niche and postmenstrual spotting. Ultrasound Obstet Gynecol .vol.37,pp.39-90,2011.

[4] AJM.Bij de Vaate, LF.van der Voet, O.Naji, M.Witmer, S.Veersema, HAM

.Brolmann, Prevalence, potential risk factors for development and symptoms related to the presence of uterine niches following Cesarean section: systematic review. Ultrasound Obstet Gynecol.vol.43,pp.72$82,2014$.

[5] BD.VaateAjm ,M.Brolmann, JW.Van Der Slikke, M. H. Emanuel, Gel instillation sonohysterography (GIS) and saline contrast sonohysterography (SCSH): comparison of two diagnostic techniques Ultrasound. ObstetGynecol.vol. 35,pp.486-489,2010.

[6] K.Litwicka, E.Greco, Caesarean scar pregnancy: a review of management options. Curr Opin Obstet Gynecol.vol.25,pp.406-461,2013.

[7] OV.Osser, L.Jokubkiene, L.Valentin, Cesarean section scar defects: agreement between transvaginal sonographic findings with and without saline contrast enhancement. Ultrasound Obstet Gynecol.vol.35,pp.75-83,2010.

[8] T.Uppal, $\quad$ V.Lanzarone, M.Mongelli,Sonographically detected caesarean section scar defects and menstrual irregularity. J Obstet Gynaecol.vol.31,pp.13-64,2011.

[9] LF.Van der Voet,AM.Bij de Vaate, S.Veersema, HAM.Brolmann,JAF .Huirne, Long term complications of caesarean section. The niche in the scar: a prospective cohort study on niche prevalence and its relation to abnormal uterine bleeding. BJOG.vol.10,pp.36-95,2014.

[10] LF.van der Voet, IP.Jordans, HA.Brölmann, S.Veersema, JA.Huirne, Changes in the uterine scar during the first year after a Caesarean section: a prospective longitudinal study. Gynecologic and Obstetric Investigation .vol.83,pp.70-164,pp.2018.

[11] AJ.Vervoort, LB.Uittenbogaard, WJ.Hehenkamp, HA.Brölmann, BW.Mol, JA.Huirne, Why do niches develop in Caesarean uterine scars? Hypotheses on the aetiology of niche development. Human Reproduction.vol.30,pp.2695-702,2015. 